\title{
A comunicação dialógica como fator determinante para os processos de ensino- aprendizagem que ocorrem na capacitação rural: um estudo de caso em um órgão público de extensão localizado no interior do Estado de São Paulo
}

\author{
The dialogic communication as a determinant for the teaching-learning processes that occur in rural \\ training: a case study in a public extension located in São Paulo, Brazil
}

Luís Fernando Soares Zuin ${ }^{\mathrm{I}}$ Poliana Bruno Zuin ${ }^{\mathrm{II}}$ Miguel Alejandro Díaz Manrique ${ }^{\mathrm{II}}$

RESUMO

O objetivo deste artigo é discutir quais caminhos ou descaminhos estão sendo percorridos nos processos de capacitação rural de extensionistas e agricultores de algumas localidades do interior do Estado de São Paulo. Para tanto, a pesquisa aqui relatada teve como pressuposto analisar as práticas pedagógicas e os processos de comunicação que ocorrem durante as capacitações formativas entre extensionistas e agricultores, bem como entre formadores e extensionistas. Buscou-se, ainda, identificar as influências da comunicação nos processos de ensino e aprendizagem, a fim de se repensar práticas relativas à comunicação que devem ser utilizadas nos processos de ensino-aprendizagem. Para tanto, o método de coleta de dados foi o estudo de caso com viés fenomenológico. Os dados anunciam a necessidade da formação continuada com orientação de profissionais da pedagogia a fim de que mudanças efetivas possam ser realizadas.

Palavras-chave: comunicação, capacitação, extensão-rural, processos de ensino-aprendizagem.

\section{ABSTRACT}

The aim of this paper is to discuss ways or diversions that are being explored in the processes of training rural extension workers and farmers in some localities of São Paulo state. To this end, the research reported here examined the pedagogical practices, and communication processes that occur during the formative training of extension workers and farmers, and between trainers and extension workers. It was further identified the communication influence in the teaching and learning in order to rethink practices related to the teachinglearning process. To this end, the data collection method was the phenomenological case study. The data herald the need of continuous training with teachers so that effective changes can be made.

Key words: communication, training, rural extension, education and learning processes.

\section{INTRODUÇÃO}

Historicamente, o Brasil foi frequentemente ofertado com uma extensão rural com viés predominantemente tecnicista. Em seus estudos, FREIRE (2006) descreveu que o modelo de extensão rural brasileiro vigente nas décadas de 1960 e 1970 era alicerçado nas práticas educativas tecnicistas, as quais foram centradas no modelo de comunicação difusionista. Uma vez que as estratégias de desenvolvimento e intervenção empregadas pelos extensionistas consideravam apenas os aspectos técnicos da produção agropecuária, sem observar as perspectivas culturais, sociais e ambientais dos produtores rurais e suas famílias. Nesse sentido, a extensão rural possuía o objetivo de divulgar e fazer com que os agricultores adotassem alguma técnica produtivista, impondo determinados conceitos ao homem do campo, não levando em conta suas experiências, interesses, vivências, conhecimentos, desejos e aspirações deles. Um contexto educativo que descaracterizava a condição de sujeito das pessoas envolvidas, ocorrendo um processo de invasão cultural. A teoria construída pelo autor ganhou destaque por questionar as ações dos órgãos de extensão e dos próprios extensionistas, bem como pelo fato de ter salientado que o trabalho deste profissional do campo é de um educador. $\mathrm{O}$ autor destaca em seu texto que a ação educadora deve estar fundamentada em uma

'Departamento de Zootecnia, Faculdade de Zootecnia e Engenharia de Alimentos, Universidade de São Paulo (USP). Av. Duque de Caxias Norte, 225, 13635-900, Pirassununga, SP, Brasil. E-mail: lfzuin@usp.br. Autor para correspondência.

"Faculdade de Tecnologia Ciências e Educação (FATECE), Pirassununga, SP, Brasil.

II'Universidad Nacional de Colombia, Bogotá D.C. Colombia. 
prática de comunicação dialógica. Para isso, é necessário considerar o agricultor inserido em uma realidade concreta e histórica, além de também levar em conta os sentidos e significados que os agricultores dão às coisas a sua volta, assim como as relações que esses sujeitos estabelecem com o mundo.

Estamos chegando ao fim da primeira década do século XXI e a literatura científica aponta que uma prática de extensão diferenciada do modelo tecnicista pouco tem ocorrido (ZUIN \& ZUIN, 2008). Os dados da pesquisa aqui discutida vão ao encontro dos apontamentos da comunidade científica de alguns anos atrás. Mas o que torna a mudança nos processos de ensino-aprendizagem no território rural uma prática tão difícil? Em suas investigações CAPORAL \& RAMOS (2006) salientam que a Política Nacional de Assistência Técnica e Extensão Rural (PNATER) estabelece que a nova ATER (Assistência Técnica e Extensão Rural) deve estar baseada nas práticas dialógicas e construtivistas. Sob esse enfoque, verificamos que a própria política busca uma prática dialógica baseada em FREIRE (2001), bem como apresenta o método construtivista para nortear os processos de ensino e aprendizagem.

Elaborada em 2004, a PNATER foi construída de forma democrática e participativa, com a intenção de contribuir para a implantação de estratégias de desenvolvimento rural sustentável, estimulando a geração de renda e trabalho no campo. Dessa forma, a Política propõe um caminho para a inclusão social da população rural brasileira mais miserável, sendo esse o elemento central de todas as suas ações, destacando o respeito que os extensionistas deverão apresentar para com às variedades sócio-econômicas, étnico-culturais e ambientais dos agricultores. Na PNATER, a ATER é considerada como um processo educativo e de fortalecimento da produção agropecuária, onde os governos devem assegurar gratuitamente a oferta de profissionais e serviços (técnicos, financeiros e gerenciais) para os agricultores que necessitam desse suporte produtivo. Portanto, a PNATER contendo um caráter educativo, salienta a necessidade de se adotar metodologias participativas, a fim de que seja concretizada a sua proposta, a PNATER estabelece que a ATER tenha como premissa promover um amplo processo de formação de formadores. Ainda que a PNATER estabeleça à nova ATER um caráter educativo com ênfase na pedagogia da prática, empregando metodologias participativas e uma pedagogia construtivista e humanista. $O$ ponto de partida deveria ser a realidade e o conhecimento local, porém essas novas propostas metodológicas ainda se encontram isoladas, sendo as práticas extensionistas, na maioria das vezes, oriundas de pesquisas científicas na literatura especializada. Portanto, necessita-se de uma reflexão sobre a prática dos extensionistas, de maneira que possa haver uma práxis nos processos formativos dos extensionistas rurais e desses junto aos agricultores.

\section{MATERIAL E MÉTODOS}

Para esta investigação, foi empregado o método de coleta de dados e informações descritas nos trabalhos de STAKE (2006). Para o autor, esse método investigativo procura coletar dados de um evento singular (único), considerando o contexto em que ocorreu. Conforme o autor, o pesquisador, sob a ótica fenomenológica, observa o evento a fim de minimizar a sua intervenção, procurando, ainda, relatar em linguagem coloquial os casos e sujeitos em suas atividades rotineiras, istoé, em seus ambientes naturais, por isso o termo naturalístico. No início da coleta de informações, o pesquisador não procura variáveis de seus interesses, ele busca eventos ou casos, tornando o seu olhar mais abrangente na captura de todo o evento e não apenas de algumas partes. Para LUDKE \& ANDRÉ (1987), esse tipo de pesquisa é de natureza qualitativa, uma vez que sempre leva em conta o contexto dos indivíduos pesquisados, por isso, o instrumento de coleta mais indicado é a entrevista.

A coleta de dados foi realizada em um órgão público localizado no interior de São Paulo que presta serviços de extensão rural e assistência técnica aos agricultores da sua região. Os sujeitos pesquisados foram: o chefe da repartição e um extensionista de sua equipe. Os dados foram categorizados a partir das enunciações dos entrevistados, a fim de descobrir os diferentes núcleos de sentido, conforme o olhar dos entrevistados. Foram escolhidas duas categorias para serem discutidas neste artigo, sendo elas: a extensão rural (o objetivo foi entender como ela é compreendida pelos extensionistas entrevistados, bem como descobrir a forma como se constituem os caminhos e descaminhos dos órgãos públicos que prestam serviços de extensão no interior do estado de São Paulo) e a comunicação (entender como ela é empregada na prática da extensão rural, ou seja, nos processos de ensino e aprendizagem entre extensionistas e agricultores). Diante do exposto, passamos a analisar cada categoria.

\section{RESULTADOS E DISCUSSÃO}

De maneira geral, a Extensão Rural do estado de São Paulo possui uma boa estrutura física, 
apresentando vários órgãos governamentais e privados que prestam os serviços de assistência técnica e extensão rural para os agricultores e pecuaristas. Em termos de formação dos extensionistas que atuam nestes órgãos de extensão e assistência técnica, são em sua maioria agrônomos, veterinários e zootecnistas, não estando presente a figura de um pedagogo. Ao indagar sobre o trabalho do extensionista e o que seria a extensão para eles, um dos entrevistados disse ser uma "paixão, adoro ser extensionista; procurei e consegui! É, ainda, o contato com o produtor, é poder ajudar... e se eu ajudar um, já fico contente!'. Ainda na opinião desse entrevistado: "a extensão é um processo de parceria. Tem que haver certa confiança. Sem confiança não se consegue nada. Essa confiança se dá pelo trabalho, pela experiência e pela associação". Conforme ZUIN \& ZUIN (2008), confiança e comprometimento são as palavras-chave para o início de qualquer tipo de relacionamento profissional, assim, para o processo de extensão rural, não poderia ser diferente. Somente por meio de uma relação de parceria orientada por diálogos entre os pares é que são construídas as relações de confiança, indicando a importância da adoção dessa postura por parte dos agricultores e extensionistas.

Indagou-se se a escolha profissional da maioria dos extensionistas era guiada pela paixão e, conforme apontaram os entrevistados, acredita-se que apenas $10 \%$ deles exerceriam a profissão por prazer. Nesse sentido, buscou-se averiguar o que levaria o extensionista a ter uma postura de descaso com a profissão e com o agricultor. A essa pergunta, os entrevistados disseram que "o próprio extensionista e o governo estragam o extensionista rural. Quem quer trabalhar não tem desilusão, mas nem todos o querem. Não há cobrança e o que se exige é muito pouco. Se você fizer o que é exigido não precisa fazer mais nada". Conforme o relato dos entrevistados, muito pouco é cobrado. Apenas pedem-se relatórios aos extensionistas. Outro aspecto levantado na entrevista diz respeito a como se dá a procura pelos serviços do extensionista rural. Eles alegam que são os produtores rurais que devem vir procurá-los e não o contrário. É interessante notar que a função do extensionista ainda não está bem definida para os próprios extensionistas, como pode ser averiguado na seguinte enunciação: "recentemente tivemos o programa Microbacias e o extensionista teve que ir atrás para que o produtor aplicasse alguma coisa". Conforme a Política Nacional de Ater (MDA, 2004, p.40), a extensão rural é um "serviço de educação não formal, de caráter continuado, no meio rural, que promove processos de gestão, produção, beneficiamento e comercialização
(...)". É interessante notar que cabe à extensão rural realizar um trabalho educativo, portanto cabe aos extensionistas irem ao encontro dos agricultores, auxiliando-os nos processos de gestão, produção e outros. Ainda com relação à extensão rural, perguntouse o que poderia ser melhorado e a resposta foi prontamente para ambos entrevistados: a parte burocrática. Segundo os entrevistados, há muitos relatórios que devem ser feitos para qualquer ação a ser desenvolvida. Outro fato elencado por eles diz respeito aos idealizadores das ações a serem desenvolvidas. Conforme a enunciação dos entrevistados, "os idealizadores acham que tudo o que fazem será aplicado em todos os lugares”. É possível notar com essa frase que, por meio dos conhecimentos advindos da experiência, os extensionistas sabem que nem sempre é possível realizar uma mesma prática de origem técnica e gerencial em diferentes contextos. Para BAKHTIN (2003), cada contexto da enunciação é único, como cada sujeito é único.

Outra questão que surgiu no decorrer da entrevista foi a respeito dos relacionamentos entre outras empresas extensionistas e o órgão de extensão rural em que o entrevistado trabalha. Os extensionistas entrevistados afirmam que nem sempre é fácil essa interação, devido às divergências de interesses. "Por exemplo, trabalhos realizados junto com instituições de apoio às pequenas empresas, às vezes, se torna muito complicado, porque nem sempre há uma parceria, aparecendo, muitas vezes, somente o nome da empresa de apoio como feitora do projeto e não a gente", afirma o extensionista. Outro exemplo relatado se refere ao fato de que "o pessoal dessas instituições dão o curso e fazem os cadastros dos produtores para depois ofertar cursos de formação". Outras ainda não se diferem das demais práticas, alertam os extensionistas, pois muitas querem saber "apenas da porteira para fora, ou seja, da comercialização”. Para os extensionistas entrevistados, a única experiência de parceria que deu certo foi com um órgão de pesquisa agropecuária governamental, por meio de aplicação a campo de um programa de desenvolvimento e aprimoramento da pecuária leiteira, beneficiando um número considerável de produtores rurais paulistas.

A questão da Comunicação como o meio em que se efetivam os processos de ensino e aprendizagem que ocorrem no campo aparece como uma das categorias mais importantes deste estudo. De acordo com um dos extensionistas, aprende-se nos cursos de formação fornecidos pelos órgãos formadores que o profissional da extensão não pode de maneira nenhuma rebaixar o produtor. Isso implica que é necessário que se tenha uma postura de A junto 
e com B e não de A para B como propunha a educação tradicional e tecnicista, em que se configuravam os processos de extensão cunhados no difusionismo da revolução verde da década de 1960 (ZUIN \& ZUIN, 2008; FREIRE, 2006). Indagou-se se eles estudaram Paulo Freire durante a graduação e depois nos cursos de formação ofertados pelos órgãos públicos de extensão rural. A resposta a essa pergunta foi negativa, demonstrando que muito pouco mudou em relação às décadas de 1960 ou 1970 nas metodologias empregadas para a capacitação e construção conjunta de novas tecnologias no campo. É interessante salientar que não há pedagogos nesses órgãos públicos e nem mesmo em instituições privadas que tratam da educação nãoformal que ocorrem nos processos de ensino e aprendizagem do meio rural.

Em uma etapa dos questionamentos, foi perguntado aos extensionistas como eram realizados os encontros com os agricultores na sede do órgão de extensão rural da região. Conforme relato dos entrevistados, essas reuniões não poderiam passar de uma hora, uma vez que se tornariam cansativas aos produtores. Novamente, verificamos os saberes advindos da experiência. Conforme SCHÖN (2000), o conhecimento que temos em diferentes situações do nosso dia-a-dia é um conhecimento tácito, ou, ainda, como define o autor, implícito, uma vez que "sabemos que sabemos", mas nem sempre conseguimos explicar o que sabemos. De acordo com o autor, o conhecimento é essencial para a prática profissional diária, pois ainda que qualquer profissional se utilize de teorias e técnicas científicas de maneira consciente, esse conhecimento tácito é importantíssimo, auxiliando o indivíduo na mediação de seus julgamentos e desempenhos satisfatórios. Assim, a prática profissional transborda acontecimentos que se repetem e, a partir deles, o profissional vai aprendendo a centrar o seu olhar, assim como responder ao que ele encontra. Diante desse fato, o autor alerta que quanto mais estável a prática de um profissional, menos ele estará sujeito a situações de surpresa e seu conhecimento tácito tenderá a se tornar automático. Contudo, alguns aspectos negativos são salientados, devido à segmentação do trabalho, à rotina repetitiva, sendo um desses aspectos: a possibilidade de perder oportunidades importantes para pensar sobre o que se está fazendo, criticar os conhecimentos tácitos e até dar novos sentidos às ações. Por isso, o autor aborda a necessidade de se refletir sobre a prática, sendo essa uma das formas que o profissional possa vir a avaliar sua prática, compreender o que está implícito em suas ações e descobrir se isso é coerente com suas crenças e compreensões pessoais. A reflexão sobre a prática pode levar o profissional a redefinir os significados de suas ações, e a partir dessas reflexões produzir no meio rural entre os pares novos conjuntos de conhecimentos e tecnologias.

Ainda conforme os entrevistados, para que os produtores venham à reunião, há que ter uma contrapartida, que é a visitação dos extensionistas a sua propriedade, mediante uma reunião prévia, que ocorre frequentemente. Dessa maneira, os extensionistas buscam estreitar os laços com os agricultores. Assim, os agricultores vão ao seu encontro e lá são discutidas ações para se colocar em prática, bem como agendamento para visitações, que ocorrem mensalmente. Foi solicitado aos entrevistados um exemplo de como era realizada a condução dos encontros. Os extensionistas fizeram um relato de uma reunião, cuja temática se circunscrevia à reprodução de gados. Inicialmente, o extensionista abordava as pendências das reuniões passadas e depois iria ao foco do tema relativo ao encontro, como, por exemplo, produtos hormonais a serem empregados em bovinos. O primeiro passo da reunião foi o relato da importância do produto e técnica aos agricultores, visando persuadilos a adotar a técnica ofertada. Perguntou-se como ocorria o processo de convencimento e a essa indagação os extensionistas responderam que "sempre se convence um produtor a partir do bolso dele. Mostra-se o tempo em que eles estão perdendo de não se fazer algo". Realizada a introdução da temática pelo extensionista é agendada a visita de um palestrante (geralmente de uma empresa de insumos) para expor novamente sobre o tema aos agricultores, reforçando o processo de persuasão da técnica para os agricultores, atitude que busca validar a tecnologia junto aos possíveis consumidores. Ao final da reunião, são agendadas visitas para o grupo de produtores convencidos da importância de se adotar a tecnologia demonstrada. Foi indagado se essa metodologia de ensino-aprendizado era participativa. Basicamente, os entrevistados repetiram aquilo que já haviam enunciado, deixando claro que a prática continua sendo tradicional, expositiva e hierárquica.

Durante os questionamentos, perguntamos se os produtores dialogavam com os extensionistas nesses encontros. A resposta foi que "os produtores falam o que pensam, mas você tem que ficar esperto para não mudar o foco. Eles começam a falar do particular. Você tem que entrar como mediador interrompendo o devaneio". Com essa enunciação, percebemos que o extensionista perde uma oportunidade ímpar enquanto educador, uma vez que, quando os agricultores começam a falar, eles estão produzindo sentidos, tentando entender os significados sociais que transmitem os extensionistas, 
a partir da sua leitura de mundo. Conforme VYGOTSKY (2001), os significados são sociais e os sentidos pessoais, assim, para que ocorra aprendizagem e a verdadeira comunicação dialógica, a qual remetia FREIRE (2006), os extensionistas têm que aproximar os sentidos do mundo dos agricultores aos sentidos das tecnologias ofertadas, e isso só será possível se ele abrir espaço à fala, escutando atentamente o enunciado dos agricultores e de outros agricultores que fazem parte da reunião. Um processo educativo e participativo, com um viés mais humanista, como prega a PNATER, tem por objetivo abrir espaço ao diálogo, o que implica saber ouvir e falar, disponibilizando tempo para isso. Por isso, os extensionistas devem abrir espaço para os relatos dos agricultores a fim de saber mais sobre cada educando, ou seja, cada agricultor. Somente compreendendo a leitura de mundo do educando é que teremos condições de realmente ensinar, por isso FREIRE (2001) salientava a importância das "rodas de conversa".

Perguntou-se se durante a aplicação da tecnologia em uma propriedade rural eles convidavam os agricultores da vizinhança para participar desse momento de capacitação. A essa pergunta a resposta foi negativa. Conforme a enunciação dos extensionistas entrevistados: "não se faz junto com outros produtores, porque outro produtor poderá ficar dando palpites, e perdemos muito tempo conversando". De acordo com o referencial aqui trazido (FREIRE, 2001), os processos de ensino-aprendizagem que ocorrem no campo devem propiciar a interação e a inter-relação entre os pares, de forma que o extensionista novamente acaba por perder momentos preciosos e propícios para uma relação de ensino e aprendizagem realmente efetiva. Antes de se tecer considerações a essa situação pedagógica, é necessário expor um relato dos extensionistas: "Em um dado momento, um extensionista estava dando capacitação a um agricultor em sua propriedade. Todavia, quando ele lá voltou para verificar como estava o andamento do emprego da nova tecnologia, teve uma grande surpresa. $\mathrm{O}$ agricultor não havia feito nada daquilo que propôs o extensionista, ao contrário disse ter feito o que o vizinho disse para fazer. Então, o extensionista que lá estava indagou: você escuta mais a mim, que sou extensionista, ou ao seu vizinho? Prontamente, o agricultor respondeu: o vizinho. Com essa resposta o extensionista disse: não tenho mais nada para fazer aqui. Virou as costas e foi embora". Tecendo reflexões sobre a prática do extensionista e do agricultor desse exemplo, verificase que para os agricultores é muito difícil mudar as suas ações, somente porque alguém de fora chega e diz ser melhor. Nem sempre é o melhor. Como arguia
FREIRE (2001), uma prática assim, em que a autoridade se revela sob um autoritarismo, não é nada além de uma invasão cultural. Ao analisar a prática do extensionista, verifica-se que, quando ele deixa de trabalhar junto com os vizinhos ou com um grupo de agricultores, ele está se colocando em uma posição de autoritarismo, porque não acredita que esse grupo possa ter conhecimentos e saberes tão válidos quanto os deles, advindos da experiência. O fato de o grupo de agricultores se unir em momentos assim soa muito mais como uma tentativa de se proteger e até mesmo de propiciar uma ajuda mútua no entendimento e compreensão das tecnologias ofertadas, porque entre o grupo acaba se estabelecendo uma relação de confiança que nem sempre é possível estabelecer com os extensionistas, já que possuem uma prática com viés autoritário.

Ainda com relação às informações obtidas e trocadas pelos agricultores, os extensionistas ressaltaram que, muitas vezes, elas advém da mídia, principalmente por influências da televisão e de alguns programas específicos sobre o mundo rural. Conforme os extensionistas, os produtores paulistas sempre possuem a informação e, às vezes, preferem empregar em sua prática aquilo que viram na televisão ao invés daquilo que disseram os extensionistas. Para exemplificar esse relato, o extensionista contou um caso de um produtor que plantou uma leguminosa que viu na TV. O extensionista não se lembrava do nome da planta, mas se recordava de que o agricultor havia pago caro por ela. A planta cresceu e então o produtor não sabia a hora de soltar o gado. Nesse momento, o produtor chamou o extensionista a fim de que pudesse auxiliá-lo. Quando lá chegou, ele viu que a leguminosa nada mais era do que pé de vassoura de bruxa, vegetal pouco produtivo para o consumo do gado. Interessante salientar que os extensionistas acreditam que quando algo de ruim acontece, a confiança fica maior. Para os entrevistados, "os produtores vêm pedir auxílio, mas fazem de outro jeito. Eles fazem da forma que sempre fizeram". A partir desse relato, perguntou-se como a comunicação ocorria entre os próprios agricultores, quando o objetivo era difundir uma nova tecnologia. Conforme a crença dos extensionistas, a comunicação que acontece entre eles é por meio "da técnica da inveja. Se o produtor vizinho observar em alguma propriedade que as coisas estão dando certo, eles também vão querer". É interessante apontar que, segundo os relatos, para os agricultores que estão junto com os extensionistas, "o proveito é melhor, o diálogo flui melhor", fato que revela a importância da parceria. Ainda sobre os processos de ensino-aprendizagem que ocorrem mediante a comunicação, perguntou-se se 
faziam uso de cartilhas e, conforme foi relatado, o uso desse tipo de material não funciona, porque os agricultores preferem que se explique o conteúdo ao invés deles lerem. No entanto, relatam ainda que após ser explicada oralmente uma nova tecnologia, quando há necessidade, os agricultores solicitam as informações por escrito. Indagou-se se os agricultores eram alfabetizados e, conforme os dados da região, a grande maioria era. Diante dessa informação, indagouse se os filhos estavam indo para a Universidade. A resposta a essa pergunta foi que apenas alguns estavam cursando a graduação, mas é interessante notar que, de acordo com os entrevistados, muitas vezes, os pais não querem que o filho continue no campo, incentivando a procura por profissões que julgam ser de maior prestígio, como: administração e direito. Perguntou-se se o espaço em que eram realizadas as capacitações possuía finalidade apenas para reuniões de definições de metas e planejamento entre extensionistas e agricultores. A resposta a essa pergunta foi negativa, pois o anfiteatro, além de ser um espaço importante "para trazer o agricultor a fim de que ele receba ofeedback", é também um espaço que é cedido para alguns bancos para passar informações sobre linhas de créditos, bem como palestras informativas com conteúdos variados de diferentes instituições.

Para concluir a coleta de dados a respeito dessas categorias de análise, buscou-se verificar se havia algum programa específico para os filhos dos agricultores para que fossem refletidas algumas práticas, como ambientes produtivos sustentáveis. Para essa questão, os extensionistas disseram existir um projeto oriundo do programa Microbacias. Além da busca de preservação ambiental, objetivo do programa, havia um projeto de educação ambiental que buscava fornecer uma capacitação formativa de conscientização ambiental e sustentável junto a alunos e professores da rede municipal de ensino da região. Essa capacitação formativa ocorre mediante o fornecimento de apostilas para professores e alunos da rede, bem como visitas a campo, a fim de mostrar os problemas da falta de saneamento, acúmulo de lixos, entre outros. Um dado interessante é que esse trabalho junto às escolas tem surtido efeitos positivos, pois as crianças acabam relatando para os pais as informações aprendidas, modificando as suas rotinas produtivas, como o relatado controle da erosão nas propriedades.

\section{CONCLUSÃO}

Buscou-se revelar por meio dessa pesquisa o quanto é necessário reconstruir as práticas de ensino e aprendizagem que ocorrem no campo e na extensão rural. Partindo do pressuposto de que os processos de ensino-aprendizagem devam culminar em uma práxis e que essa resulte em uma sociedade sustentável e mais humanitária, faz-se necessária uma prática centrada na comunicação dialógica junto e com os produtores rurais, a fim de se tecer uma nova realidade rural. Portanto, os extensionistas não podem efetuar mudanças na atitude dos agricultores sem antes conhecer a visão de mundo que eles possuem e sem antes confrontá-los com a sua totalidade. Aimportância do extensionista e dos órgãos de extensão é revelada em sua total magnitude, desde que revejam a sua prática e considerem os aprendizes como sujeitos que estão inseridos em uma cultura e que possuem também uma leitura de mundo.

Entretanto, há um indicativo de que as dificuldades em se romper com o paradigma tecnicista de extensão rural consistem na própria finalidade da extensão na sociedade capitalista, ou seja, estender conhecimentos aos produtores a fim de incorporá-los na sociedade mercadológica das empresas de insumos e serviços tecnológicos. Por outro lado, pelo fato de haver, na atualidade, a necessidade de um desenvolvimento sustentável no país, seja por conta dos ambientes institucionais, seja pelas necessidades do consumidor, há uma maior pressão para que a ATER modifique as suas práticas. Nesse sentido, a definição das novas políticas para o desenvolvimento sustentável agropecuário relata que é fundamental um processo produtivo que não seja alicerçado apenas na transferência de tecnologias (prática extensionista tradicional e frequente), mas que empreguem em suas rotinas pedagógicas metodologias participativas de construção conjunta de novos conhecimentos entre extensionistas e agricultores, sendo imprescindível a figura de pedagogos na formação continuada dos extensionistas rurais e na própria extensão rural.

\section{REFERÊNCIAS}

BAKHTIN, M. Estética da criação verbal. São Paulo: Martins Fontes, 2003. p.476.

CAPORAL, F.R.; RAMOS, L.F. Da extensão rural convencional à extensão rural para o desenvolvimento sustentável: enfrentar desafios para romper a inércia. Disponível em:<http://www.ematerce.ce.gov.br/empresa/ artigo.php?codigo $=17>$. Acesso em: 10 jun. 2006 .

FREIRE, P. Extensão ou comunicação? Petrópolis: Paz e Terra, 2006. p.96.

FREIRE, P. Pedagogia da autonomia. Petrópolis: Paz e Terra, 2001. p.152.

LÜDKE, M.; ANDRÉ, M.E.D.A. Pesquisa em educação: abordagens qualitativas. São Paulo: Atlas, 1987. p.99. 
Ministério do Desenvolvimento Agrário (MDA). Política nacional de assistência técnica e extensão rural. Disponível em: <http://comunidades.mda.gov.br/portal/saf/ arquivos/view/ater/Pnater.pdf>. Acesso em: 02 maio, 2004.

SCHÖN, D. Educando o profissional reflexivo: um novo design para o ensino e a aprendizagem. Porto Alegre: Artes Médicas Sul, 2000. p.256.
STAKE, R. A arte de investigação com estudos de caso. Lisboa: Gulbenkian, 2006. p.187

VYGOTSKY, L.S. A construção do pensamento e da linguagem. São Paulo: Martins Fontes, 2001. p.496.

ZUIN, L.F.S.; ZUIN, P.B. Produção de alimentos tradicionais: extensão rural. Aparecida: Idéias \& Letras, 2008. p. 224. 